\title{
Allocation of zones with different responses of ground movement individual indicators to standard seismic impact
}

\author{
Vladislav Zaalishvili* \\ Geophysical Institute of the Vladikavkaz Scientific Center of the Russian Academy of Sciences, \\ 362002, Vladikavkaz, Russia
}

\begin{abstract}
The paper presents the results of calculating the vibrations of the soil strata using the ZOND- (linear) program. Accelerograms of earthquakes recorded in Tbilisi (12/14/2000) and Athens (09/7/1999) on rocky soils were set as a standard seismic action in the bedrock of a loose soil layer. The maximum amplitudes of records and the soil vibrations real spectrum areas were considered as the soil movement indicators. The ratios of the presented indicators to the corresponding values of the initial values were calculated. The results obtained in the form of the indicators' ratios for the soil movement in the areas under consideration were used to differentiate soils by their response to standard seismic action. Differentiation of soils in the corresponding areas was carried out in three groups according to the value of this ratio. The zones of soil reaction to the standard seismic action were identified. The sites of the third group are tentatively assigned to the most dangerous areas in terms of seismicity. Due to the fact that the calculations were based on a linear-elastic representation of the soils' behavior, typical for small deformations, the data obtained are preliminary methodological in nature and will be refined in the future.
\end{abstract}

\section{Introduction}

In recent years, the list of studies, in which instrumental measurements are very actively used in various, very different fields of geophysics, has significantly expanded. This undoubtedly raised the quality of the results obtained and their reliability [1-9]. In this regard, it became possible to directly study such subtle effects as nonlinearity, which is clearly manifested during macro-seismic and other field surveys of various hazardous natural and man-made processes' manifestations. At the same time, it should be noted that the physical nonlinearity manifestations of the soils under strong impacts have been little studied.

The results of previous geophysical studies on the territory of Vladikavkaz in the process of implementation in 1969-2006 by various scientific institutions on seismic microzoning work of the city territory have been analyzed.

\footnotetext{
* Corresponding author: vzaal@mail.ru
} 
Past works clearly reflect the evolution of ideas about the factors that form the earthquakes' seismic effect. To clarify various parameters of the soil strata, modern measuring instruments and equipment were used: Georadar "OKO-2", electric exploration station EES-1 and seismic station of station "Lakkolit H-2M". This made it possible to control the data obtained during the study. The equipment specified in the complex is based on the results of the domestic instrument-makers' latest achievements at the level of world standards and is provided with modern programs for computer processing of field materials.

\section{Evaluation of the soils' seismic properties in various ways}

In accordance with building codes seismic stiffness method is obligatory for use as the main one at objects of seismic microzoning of all classes. The intensity increment was determined using the well-known formula of S.V. Medvedev [10, 11]. As a result of generalization of the results of studies carried out for the entire territory of the city, for the average soil conditions, the following characteristics were adopted: $v_{s}=350 \mathrm{~m} / \mathrm{s}$ and $\rho=$ $1,85 \mathrm{t} / \mathrm{m}^{3}$. In addition, the calculations were carried out according to the modified Maksimov-Zaalishvili formula, taking into account the resonant properties of soils at low impact levels $[10,11]$ :

$$
\Delta I_{\mathrm{MZ}}=\lg \left(\frac{\rho_{0} v_{0}}{\rho_{i} v_{i}} e^{2,5\left(\lg v_{0}-\lg v_{i}\right)}\right)
$$

Which made it possible to increase the validity of the results obtained.

The groundwater level in the territory of Vladikavkaz is located at a depth of 100-150 m in pebbles with an amount of aggregate $<30 \%$. Thus, the increment in seismic intensity due to the groundwater influence is zero.

The next instrumental method of seismic microzoning, mandatory for application, is the method of registering earthquakes. Pebble ground conditions at GEO Station were taken as average ground conditions. This assignment is due to the amount of aggregate in the gravel $>30 \%$.

A significant influence of soil conditions on the amplitude-frequency characteristics of the records of the matched areas was established and dangerous vibration frequencies were identified (Table 1).

Table 1. Seismic intensity increments based on earthquake records

\begin{tabular}{|c|c|c|c|}
\hline Station code & $\Delta \mathrm{I}$ & $\Delta \mathrm{I}$ & $\Delta \mathrm{I}$ \\
& $\mathrm{SC}-1 \mathrm{P}$ & $\mathrm{S}-5-\mathrm{S}$ & \\
\hline MUS & -0.1 & -0.1 & 0 \\
\hline GEO & 0 & 0 & 0 \\
\hline HOL & 0.4 & 0.6 & 1 \\
\hline TEA & -0.2 & -0.6 & -1 \\
\hline BUR & - & -0.2 & 0 \\
\hline TUR & - & 0.3 & 0 \\
\hline
\end{tabular}

Micro-seismic method is auxiliary and is used in combination with other methods. The results of determining the seismic intensity increments from the micro-seismic records obtained at the points of the seismological observation network are shown in Table 2, the results of using mobile stations will be considered later.

Table 2. Seismic intensity increments from micro-seismic records 


\begin{tabular}{|c|c|c|c|}
\hline Station code & $\Delta \mathrm{I}$ & $\Delta \mathrm{I}$ & $\Delta \mathrm{I}$ \\
& $\mathrm{SC}-1 \mathrm{P}$ & $\mathrm{S}-5-\mathrm{S}$ & \\
\hline MUS & -0.95 & -0.20 & 0 \\
\hline GEO & 0 & 0.00 & 0 \\
\hline HOL & 0.03 & 0.68 & -1 \\
\hline TEA & -1.05 & -0.60 & 0 \\
\hline BUR & - & -0.20 & 0 \\
\hline TUR & - & 0.25 & \\
\hline
\end{tabular}

The use of stationary points for recording microseisms made it possible to determine the daily variations in the amplitudes of micro-seismic vibrations in different parts of the Vladikavkaz city. The use of the micro-seismic records' amplitudes to estimate the soil intensity increment is usually characterized by high uncertainty. Obviously, the proximity of industrial facilities to the location of the "Geo-center" station causes an overestimation of the amplitudes of micro-vibrations at this station (enterprises operate 24 hours), in addition, the "Theatre" station is located in sufficient proximity to the Terek River, which is also a powerful source of micro-vibrations.

In 1970, along with the traditional methods and methods of assessing the seismic properties of soils, for the first time, a computational method was used in the form of a seismic microzoning RWM method, which made it possible to take into account the vibrations of a thick soil layer during earthquakes.

Using the calculation method, as a RWM (reflected wave method), the synthetic records obtained by the stochastic method for the Sunzhenskaya zone of the WHO (western branch) and for the Vladikavkaz fault due to the close proximity to the city limits, were used as input accelerograms - the accelerogram obtained using the FINSIM program. In addition, the instrumental records of real strong earthquakes recorded in various regions of the world were used. To predict the soils' behavior under intense seismic loads, the NERA program was used, which allows taking into account the soils' nonlinear properties. The external seismic action was specified in the form of a synthetic accelerogram of a strong earthquake for the Vladikavkaz fault with a magnitude $\mathrm{M}_{\max }=7.1$.

The assessment of the thick soil layer influence on the spectral features of vibrations was carried out using several models based on data from a schematic geological and geophysical section. The influence of a thick stratum can manifest itself at frequencies of $0.4 \mathrm{~Hz}$ and 1.2-1.6 Hz.

Based on the results of modeling and subsequent calculations using strong earthquakes, the vibration amplification curves of the considered upper stratum of the section in relation to the underlying layer of dense gravel were plotted.

To detail the results of the instrumental method and clarify the boundaries of the geological engineering zoning map, the records of micro-seismic vibrations were made in the city of Vladikavkaz in various parts of the city, covering its entire territory. The registration of microseisms was carried out by three mobile seismic stations, including seismic signal recorders (SSR) "Delta-Geon-02M" and seismic receivers SC-1P. As a result of this work, a map of the prevailing vibration frequencies in the territory of the Vladikavkaz city was built.

Despite the differences observed for some areas in the theoretical and instrumental data observed in the region of higher frequencies (which is explained by the greater influence of the accuracy of determining the layers' thickness with an increase in seismic wave velocity and a decrease in the thickness of these layers), some general regularities can be identified. For the areas of fluid consistency of clayey soils, the maximum amplification of vibration amplitudes and a decrease in resonance frequencies in the range of $1.7-6 \mathrm{~Hz}$ are observed. 
In the area, composed of clayey soils of semi-solid consistency, the amplification of vibrations, in general, is less than half and the resonance frequencies will be 6-7 Hz. For the top layer of gravel with filler $>30 \%$ the spectral amplitudes are somewhat smaller, the main spectral peak is at a frequency of $10-12 \mathrm{~Hz}$; for gravel with filler $<30 \%$ spectral peak corresponds to $19 \mathrm{~Hz}$ ("Metallurgic" area) and higher [10,11].

For the first time, we used a new, instrumental - computational method developed by us earlier, the application of which is based on the direct use of a database of strong movements of the K-NET type in the form of real records for the strong earthquakes registered in various regions of the world.

When using the instrumental-calculation method in the form of the instrumental analogies method for the calculations from the database of strong movements of the Geophysical Institute, which includes almost 70,000 records. At the same time, the records of earthquakes were selected in the areas with similar soil conditions and earthquake characteristics (magnitude, epicentral distance, etc.).

At present, there is a need for seismic microzoning of territories not only in large cities of Russia. Seismic microzoning maps of some large cities were created 25 years ago. At the same time, the urbanized areas are not a frozen entity. The distribution of buildings is changing, the physical state of the foundation grounds is changing. The "flooding" of territories, characteristic of urbanized areas, occurs. During this time, the existing scientific principles for assessing seismic hazard were created and developed, the level of seismic hazard itself has changed.

In order to improve various methods of seismic microzoning in the territory of Tbilisi, the areas with different engineering and geological conditions were selectively identified. The allocated areas covered practically all the features of the engineering and geological conditions of the city and were fairly evenly dispersed throughout the city. Considering the methodological nature of the work and the ongoing development of criteria for the selection of sites, we did not force the increase in the number of sites.

The soil sections were transformed into special soil models using the previously described method [10]. In these models, the following were introduced as the soil layer characteristics: layer thickness $\mathrm{H}(\mathrm{m})$, shear wave velocity VS $(\mathrm{m} / \mathrm{s})$ and soil layer density $\rho\left(\mathrm{t} / \mathrm{m}^{3}\right)$. Absorption $\alpha(\mathrm{m}-1)$ can be taken into account in the calculations, but for the "purity" of the experiment, it was not used in the calculations. Two accelerograms recorded on rocky ground during earthquakes with the characteristics similar to those expected were used as the initial seismic effects. In this case, the accelerograms were considered for epicentral distances of $12 \mathrm{~km}$ (accelerogram of an earthquake registered in Tbilisi on December 14, 2000 at the Department of Regional Seismology of the Institute of Geophysics of the Georgian Academy of Sciences) and $22 \mathrm{~km}$ (an accelerogram of an earthquake recorded in Athens on September 7, 1999 by the Institute of Geodynamics of Greece).

The calculations of vibrations were made on the basis of a linear elastic representation of the soils' behavior using the ZOND- (linear) program developed earlier [10]. The vibrations of the soil on the strata surface were calculated. The maximum amplitudes of records and areas of the soil vibrations' real spectrum were considered as the soil response indicators (Table 3.). The area of the real spectrum, in fact, is the energy characteristic of the vibrations formed in the soil mass [11].

Table 3. Ratios of the calculated accelerograms' indicators in the territory of Tbilisi

\begin{tabular}{|c|c|c|c|c|}
\hline \multirow{3}{*}{ plot no. } & \multicolumn{2}{|c|}{$\begin{array}{c}\text { Earthquake no. 1 } \\
\text { (Tbilisi) }\end{array}$} & \multicolumn{2}{c|}{$\begin{array}{c}\text { Earthquake no. } 2 \\
\text { (Athens) }\end{array}$} \\
\cline { 2 - 5 } & $\begin{array}{c}\text { Maximum record } \\
\text { acceleration ratio }\end{array}$ & $\begin{array}{c}\text { Area ratio of } \\
\text { real spectra }\end{array}$ & $\begin{array}{c}\text { Maximum } \\
\text { record }\end{array}$ & $\begin{array}{c}\text { Area ratio of real } \\
\text { spectra }\end{array}$ \\
\hline
\end{tabular}




\begin{tabular}{|c|c|c|c|c|}
\hline & $\mathrm{a}_{\mathrm{i}}^{\max } / \mathrm{a}_{0}{ }^{\max }$ & $\mathrm{S}_{\mathrm{i}} / \mathrm{S}_{0}$ & $\begin{array}{c}\text { acceleration } \\
\text { ratio } \\
\mathrm{a}_{\mathrm{i}}^{\max } / \mathrm{a}_{0}{ }^{\text {max }}\end{array}$ & $\mathrm{S}_{\mathrm{i}} / \mathrm{S}_{0}$ \\
\hline 1 & 1.6 & 1.4 & 1.4 & 1.6 \\
\hline 2 & 2.0 & 1.3 & 1.9 & 1.6 \\
\hline 3 & 1.4 & 1.2 & 1.3 & 1.5 \\
\hline 4 & 1.5 & 1.5 & 1.7 & 1.6 \\
\hline 5 & 1.6 & 1.4 & 1.8 & 1.3 \\
\hline 6 & 1.3 & 1.2 & 2.0 & 1.4 \\
\hline 7 & 1.3 & 1.2 & 1.4 & 1.4 \\
\hline 8 & 2.8 & 2.3 & 3.7 & 2.5 \\
\hline 9 & 1.9 & 1.8 & 2.5 & 2.1 \\
\hline 10 & 1.9 & 1.7 & 3.0 & 2.4 \\
\hline 11 & 3.1 & 3.1 & 3.0 & 3.3 \\
\hline 12 & $2 . .9$ & 2.1 & $2 . .4$ & $2 . .2$ \\
\hline 13 & 3.4 & 2.4 & 2.2 & 1.6 \\
\hline 14 & 1.8 & 1.0 & 1.5 & 1.5 \\
\hline 15 & 2.7 & 2.5 & 2.5 & 2.0 \\
\hline 16 & 2.6 & 2.1 & 3.5 & 3.0 \\
\hline 17 & 3.7 & 2.7 & 3.6 & 3.0 \\
\hline 18 & - & - & - & - \\
\hline 19 & 2.2 & 2.2 & 1.8 & 1.8 \\
\hline 20 & 3.1 & 2.6 & 3.9 & 2.7 \\
\hline 21 & 3.7 & 2.8 & 2.3 & 2.5 \\
\hline 22 & 2.2 & 1.8 & 1.3 & 1.6 \\
\hline 23 & 2.0 & 1.5 & 2.2 & 1.5 \\
\hline 24 & 1.5 & 1.3 & 1.2 & 1.5 \\
\hline 25 & 1.9 & 1.9 & 3.0 & 2.9 \\
\hline 26 & 1.6 & 1.1 & 1.6 & 1.4 \\
\hline 27 & 1.2 & 1.0 & 1.0 & 1.1 \\
\hline 28 & 1.5 & 1.3 & 1.2 & 1.2 \\
\hline 29 & 2.5 & 2.2 & 1.8 & 1.8 \\
\hline 30 & 1.3 & 1.1 & 1.2 & 1.3 \\
\hline 31 & 2.8 & 2.4 & 1.9 & 1.9 \\
\hline 32 & 3.3 & 2.7 & 1.8 & 2.0 \\
\hline 33 & 2.1 & 1.5 & 1.4 & 1.4 \\
\hline 34 & 2.5 & 1.8 & 1.9 & 1.9 \\
\hline 35 & 2.3 & 1.6 & 1.7 & 1.5 \\
\hline 36 & 1.8 & 2.9 & 3.7 & 1.9 \\
\hline 37 & 2.9 & 3.3 & 4.8 & 3.6 \\
\hline 38 & 2.0 & 1.5 & 2.5 & 1.6 \\
\hline 39 & 3.1 & 2.2 & 1.3 & 1.7 \\
\hline 40 & - & - & - & - \\
\hline 41 & 1.8 & 2.2 & 2.4 & 1.7 \\
\hline 42 & 1.7 & 1.4 & 1.4 & 1.3 \\
\hline 43 & 1.2 & 1.3 & 1.0 & 1.5 \\
\hline 44 & 2.0 & 1.8 & 1.2 & 1.4 \\
\hline 45 & 2.5 & 2.2 & 3.5 & 2.3 \\
\hline 46 & 2.8 & 2.8 & 3.1 & 2.6 \\
\hline
\end{tabular}




\begin{tabular}{|l|l|l|l|l|}
47 & 2.8 & 2.8 & 4.3 & 3.4 \\
\hline
\end{tabular}

Table 4. Ratios of soil movement indicators

\begin{tabular}{|lr|c|c|}
\hline \multirow{2}{*}{ Group no. } & \multicolumn{2}{|c|}{ Ground movement indicator } \\
\cline { 3 - 4 } & & $\begin{array}{c}\text { The ratio of the } \\
\text { vecording ground } \\
\text { vibrations' maximum } \\
\text { accelerations } \\
a_{i}^{\max } / a_{0} \max \end{array}$ & $\begin{array}{c}\text { The ratio of the soil } \\
\text { vibrations' real spectrum } \\
\text { areas } \\
\mathrm{S} / \mathrm{S}_{0}\end{array}$ \\
\hline Article I. & I & $1-2$ & $1-1.5$ \\
\hline Article II. & II & $2.1-3$ & $1.51-2.5$ \\
\hline Article III. & III & $>3$ & $>2.5$ \\
\hline
\end{tabular}

Further, the ratios of these indicators to the corresponding initial indicators of the seismic standard action conditions (i.e., for rocky soils) were calculated. The results obtained in the form of soil movement indicators' ratios of the sections under consideration were used to differentiate the soils according to their response to standard seismic action (Table 4).

The data for both earthquakes were divided into groups. The analysis of the obtained results showed that the number of sections allocated according to the above-mentioned criterion for both traffic indicators differs slightly: I group - 17 sections, II group - 15 sections, III group - 11 sections. There are 3 areas, which, according to their reaction level, correspond to intermediate positions. In addition, for a number of reasons, the calculation results for some sections were not used (sections 18 and 40).

It should be noted that, for all three groups, the results of calculations for both earthquakes, in general, are in good agreement. This indicates, in particular, a fairly reasonable selection of different areas in the city by the level of reaction of both indicators in the linear-elastic formulation.

On the basis of these data, the territory was zoned according to the maximum ground accelerations (Figure 1) and the vibration spectra were zoned according to the areas. In other words, zones of soil reaction to standard seismic action were identified.

In the future, it is planned to use the currently developed computer programs for calculating the soil strata fluctuations of the Tbilisi territory based on the nonlinear soil properties' consideration.

In this regard, it should be noted that an increase in the number of sites will allow uniformly filling the space on the zoning map of "iso-reaction" in the city territory and compiling a picture of the distribution of zones with different seismic hazards close to real conditions. In addition, the distribution maps of the soil vibrations' natural periods throughout the city will be compiled.

Of greatest interest are the features of 9 sites assigned to Group III. At this stage of the study, these areas are tentatively classified as the most dangerous areas in terms of seismicity. This is due to the fact that the calculations were based on the linear elastic representation, which is typical for small deformations. In this regard, the data obtained are preliminary and will be clarified in the future. 


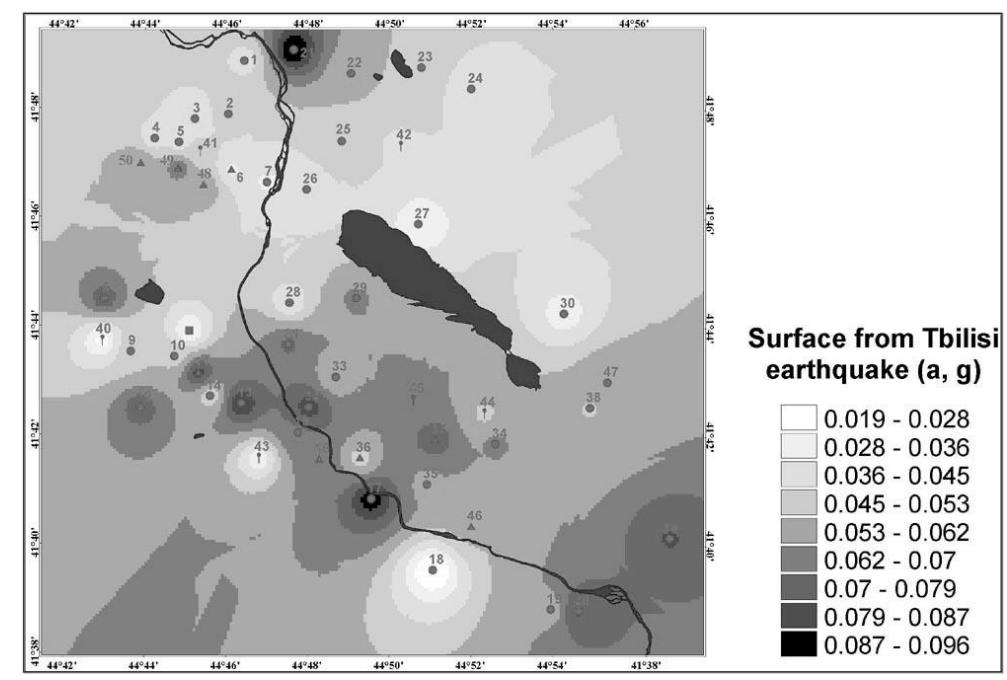

Fig.1. Territory zoning based on maximum soil acceleration (earthquake no.1)

\section{Conclusion}

Based on the calculations, it has been established that such a parameter as the vibrations' real spectrum area, is a reliable and quite reliable indicator of such a feature of the soil stratum as its characteristic of its stress-strain state level and an indicator of its seismic properties.

\section{References}

1. V. Zaalishvili, D. Melkov, B. Dzeranov, F. Morozov, G. Tuaev, International Journal of GEOMATE 15(47), 158-163 (2018).

2. A. Shempelev, V. Zaalishvili, S. Kukhmazov, Geotectonics 51(5), 479-488 (2017).

3. V. Zaalishvili, A. Kanukov, D. Melkov, V. Makiev, L. Dzobelova, International Journal of GEOMATE 15(51), 160-166 (2018).

4. V. Zaalishvili, D. Melkov, A. Kanukov, B. Dzeranov, V. Shepelev, International Journal of GEOMATE 10(1), 1670-1674 (2016).

5. V. Zaalishvili, E.A. Rogozhin, Open Construction and Building Technology Journal 5, 30-40 (2011).

6. V.B. Zaalishvili, International Journal of GEOMATE 10 (2), 1706-1717 (2016).

7. A.V. Gorbatikov, E.A. Rogozhin, M.Yu. Stepanova, Yu.V. Kharazova, N.V. Andreeva, F.V. Perederin, V.B. Zaalishvili, D.A. Melkov, B.V. Dzeranov, B.A. Dzeboev, A.F. Gabaraev, Physics of the Earth 1, 28 (2015).

8. V. Zaalishvili, D. Melkov, Izvestiya. Physics of the Solid Earth 50(5), 707-718 (2014).

9. G.S. Grigorkina, A.G. Ramonova, D.D. Kibizov, E.N. Kozyrev, V.B. Zaalishvili, T.T. Magkoev, K. Fukutani, Solid State Communications 257, 16-19 (2017).

10. V.B. Zaalishvili, Institute of Physics of the Earth named after O. Yu. Schmidt of the Russian Academy of Sciences (IPE RAS), 2000.

11. V.B. Zaalishvili, (Sience, 2009). 